\title{
Visible Light Photocatalysis with Rare Earth Ion-Doped $\mathrm{TiO}_{2}$ Nanocomposites
}

\author{
Himanshu Narayan, ${ }^{1}$ Hailemichael Alemu, ${ }^{2}$ Lijeloang Setofolo, ${ }^{2}$ and Lebohang Macheli \\ ${ }^{1}$ Department of Physics \& Electronics, National University of Lesotho, Roma 180, Lesotho \\ ${ }^{2}$ Department of Chemistry \& Chemical Technology, National University of Lesotho, Roma 180, Lesotho \\ Correspondence should be addressed to Himanshu Narayan, h.narayan@nul.ls and Hailemichael Alemu, hm.alemu@nul.ls
}

Received 28 September 2011; Accepted 25 October 2011

Academic Editors: J. M. Farrar and P. L. Gentili

Copyright (C) 2012 Himanshu Narayan et al. This is an open access article distributed under the Creative Commons Attribution License, which permits unrestricted use, distribution, and reproduction in any medium, provided the original work is properly cited.

\begin{abstract}
Rare earth $(\mathrm{R})$ ion-doped $\mathrm{TiO}_{2}$ nanocomposites (NCs) with general composition $\left[\mathrm{R}_{2} \mathrm{O}_{3}\right]_{x} \cdot\left[\mathrm{TiO}_{2}\right]_{1-x}(\mathrm{R}: \mathrm{Y}, \mathrm{Yb}, \mathrm{Gd} ; x=0.1,0.2)$ were synthesized through co-precipitation/hydrolysis $(\mathrm{CPH})$. NC particles with average size of approximately a few tens of nm were obtained. Similar compositions of polycrystalline (PC) samples with larger particle size were also prepared employing solid state reaction (SSR) method. Visible light photocatalytic activity of all samples was investigated for degradation of Congo red (CR) dye. Both in terms of apparent rate constant $\left(k_{\text {obs }}\right)$ and percent degradation after $180 \mathrm{~min}\left(C_{180}^{\prime}\right)$, all NCs produced significantly enhanced degradation as compared to pure $\mathrm{TiO}_{2}$ and $\mathrm{PC}$ samples. Best degradation of $95 \%\left(C_{180}^{\prime}\right.$ value) resulted with $x=0.2$ composition of $\mathrm{Y}^{3+}$ doped NC with $k_{\mathrm{obs}}=2.6 \times 10^{-2} \mathrm{~min}^{-1}$. This was followed by $C_{180}^{\prime}$ of 85 and $80 \%$, produced with $\mathrm{Yb}^{3+}$ and $\mathrm{Gd}^{3+}$ doped, $x=0.1 \mathrm{NCs}$, at $k_{\mathrm{obs}}$ around $1.0 \times 10^{-2}$ and $0.9 \times 10^{-2} \mathrm{~min}^{-1}$, respectively. The observations clearly suggest that enhanced photocatalytic degradation of CR is directly related to smaller particle size of the catalysts. Moreover, the presence of rare earth ions in the composites facilitates further improvement of degradation efficiency through effective suppression of $\mathrm{e}^{-} / \mathrm{h}^{+}$ recombination.
\end{abstract}

\section{Introduction}

Among several applications associated with titanium dioxide $\left(\mathrm{TiO}_{2}\right)$, photocatalysis is perhaps the most important one [1, 2]. For the treatment of wastewater through photocatalytic degradation of pollutants, it is well known to form the host in a number of doped catalysts [3-8]. Even as a pure material, $\mathrm{TiO}_{2}$ produces reasonable degradation, which is usually limited by the high rate of charge $\left(\mathrm{e}^{-} / \mathrm{h}^{+}\right)$recombination, large particle size, and the requirement of UV irradiation (because the $3.2 \mathrm{eV}$ band-gap of pure $\mathrm{TiO}_{2}$ corresponds to an absorption band-edge of about $390 \mathrm{~nm}$ ) to induce photocatalytic reactions $[1,2,5-7,9-11]$. While planning to synthesize improved catalysts, one needs to take into account all these factors that may substantially deteriorate the degradation efficiency of the resulting material.

Contrary to many previous reports, our recent investigations have shown that it is the $\mathrm{e}^{-} / \mathrm{h}^{+}$recombination that hampers the efficiency of photocatalytic degradation most severely [5-7]. Nevertheless, it can be controlled to a large extent by the use of an appropriate dopant that can capture the photogenerated electrons in the material. Transition metals $[4,6-8,12]$ and rare earth ions $[5,6,13-$ 18], with high oxidation states, seem to be the suitable candidates for this purpose. We have further noted that photosensitization is the predominant mechanism in $\mathrm{TiO}_{2}$ mediated photocatalysis, which is supported by smaller particle size. Fortunately, this requirement of smaller particles also diminishes the need of UV irradiation. This is because in the process of photosensitization, catalysts do not absorb the irradiation directly, rather the pollutants attached to the catalyst particles do. Smaller particles are easily covered by the adsorbed pollutants (e.g., dyes). Once the catalyst surface is covered, effectively the colour of the latter determines the required excitation wavelength, thus making the visible light induced photocatalysis possible. It is noteworthy, however, that at very small particle dimensions, $\mathrm{e}^{-} / \mathrm{h}^{+}$recombination could become significantly high owing 
to smaller mean free path available to the free charges, and this could result in reduction of the photocatalytic activity instead of improvement. It has been reported that there exists a critical particle size (from XRD data) of about $10 \mathrm{~nm}$, above which the rate of recombination does not vary too much [9].

We have already reported as high as 95\% degradation of the dye Congo red (CR) in $180 \mathrm{~min}$ and a reasonably high rate of $2.74 \times 10^{-2} \mathrm{~min}^{-1}$, with $\mathrm{TiO}_{2} \mathrm{NCs}$ doped with 0.2 and 0.1 molar concentration of $\mathrm{Y}^{3+}$ ions, respectively [5]. With these encouraging results and the background mentioned previously, it was crucial to investigate the performance of $\mathrm{TiO}_{2}$ photocatalysts doped with other rare earth ions. It is noteworthy to mention here that many authors have recently reported about efficient photocatalytic activity of rare earth ion-doped $\mathrm{TiO}_{2}$ composites [12-18].

Congo red (molecular structure shown in Figure 1) is a harmful azo dye that is abundantly found in the wastewater from textile industries. Photocatalytic degradation of CR is believed to be a suitable method of treatment because it usually produces molecular nitrogen instead of the unsafe nitrates [9]. In this article, which is essentially an extension of our previous work, we report, for the very first time, the results of visible light-induced photocatalytic degradation of $\mathrm{CR}$ under the influence of $\mathrm{Yb}^{+}$- and $\mathrm{Gd}^{3+}$-doped, nanosized $\mathrm{TiO}_{2}$ photocatalysts. The initial expectation from this investigation was to establish the role of rare earth ions in the degradation process, as well as to determine the most efficient photocatalyst in terms of the doping. We present the results in comparison to those obtained earlier with similar NCs doped with $\mathrm{Y}^{3+}$ ions [5] and also discuss the effects of particle size.

\section{Experimental}

2.1. Material Synthesis. In our earlier work with the $\mathrm{Y}^{3+}$ doped $\mathrm{TiO}_{2}$ materials [5], we had observed that the most efficient photocatalysts were the NCs doped with a molar fraction $x \leq 0.2$. This observation pointed out to the possibility of existence of an optimum doping concentration (molar fraction $x_{c}$, say), which is apparently less than or around $x=0.2[6]$. Therefore, in this work, we synthesized the composites with $x=0.1,0.2$ only, with general composition $\left[\mathrm{R}_{2} \mathrm{O}_{3}\right]_{x} \cdot\left[\mathrm{TiO}_{2}\right]_{1-x}$ (where R: Y, Yb, Gd), employing the method of chemical coprecipitation followed by hydrolysis $(\mathrm{CPH})$. Same procedures, as reported earlier [5-7], were followed in the synthesis.

The starting materials for the rare earth dopants were the nitrates $\mathrm{R}\left(\mathrm{NO}_{3}\right)_{3} \cdot 6 \mathrm{H}_{2} \mathrm{O}$ procured from Aldrich Chemicals. Other chemicals used in the synthesis were npropanol $(\mathrm{BDH})$, iso-propanol (UNILAB, SA), tetrabutylorthotitanate (Fluka), and nitric acid (ACE, SA). The CR used in these experiments was also obtained from Aldrich Chemicals. First, the oxides $\left(\mathrm{R}_{2} \mathrm{O}_{3}\right)$ were precipitated from nitrate solution that was prepared by dissolving the nitrate in isopropyl alcohol and heating the mixture for 30 minutes at $65^{\circ} \mathrm{C}$ with continuous stirring. The $\mathrm{pH}$ of the solution was raised to 6.5 by slowly adding a $3.5 \mathrm{M} \mathrm{NH}_{4} \mathrm{OH}$ solution in isopropyl alcohol, to precipitate the nitrate precursor.

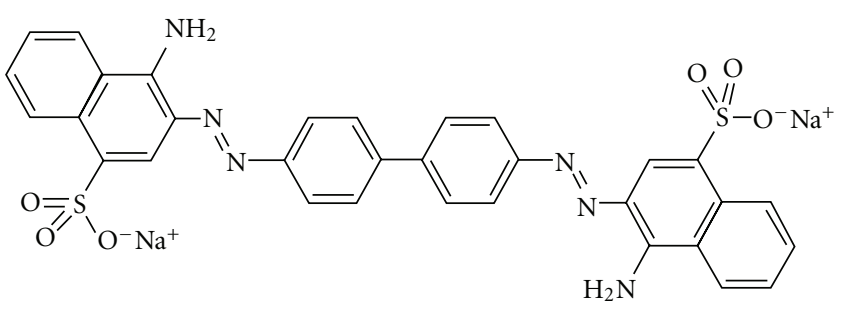

Figure 1: Molecular structure of Congo red dye.

Then approximately $10 \mathrm{~g}$ of distilled and deionized water was added dropwise into the solution and was stirred for 45 minutes. A solution of tetrabutyl-orthotitanate $\left\{\mathrm{Ti}(\mathrm{OBu})_{4}\right\}$ and isopropyl alcohol, prepared in a ratio of $1: 2$ by weight, was added dropwise to the coprecipitated $\mathrm{R}_{2} \mathrm{O}_{3}$ solution for controlled hydrolysis with $\mathrm{H}_{2} \mathrm{O}: \mathrm{Ti}(\mathrm{OBu})_{4}$ in the ratio of $25: 1$. The final solution was kept stirred for 90 minutes at $65^{\circ} \mathrm{C}$, filtered, and then dried at 100 and $220^{\circ} \mathrm{C}$, respectively. The prepared $\left[\mathrm{R}_{2} \mathrm{O}_{3}\right]_{x} \cdot\left[\mathrm{TiO}_{2}\right]_{1-x}$ nanoparticles were then calcined in a flowing air atmosphere at $500^{\circ} \mathrm{C}$ for three hours. The $\mathrm{Y}^{3+}$-doped NC samples from our previous work [3] were used as the first set, and the other two sets doped with $\mathrm{Yb}^{3+}$ and $\mathrm{Gd}^{3+}$, respectively, were synthesized following the above mentioned procedure.

For the preparation of polycrystalline (PC) composites, the method of solid-state reaction [SSR] was employed. First, the rare earth oxides $\left(\mathrm{R}_{2} \mathrm{O}_{3}\right)$ were prepared by heating the nitrate for about one hour at $450^{\circ} \mathrm{C}$. Stoichiometric amounts of highly pure (99.9\%) $\mathrm{TiO}_{2}$ and freshly prepared $\mathrm{R}_{2} \mathrm{O}_{3}$ were taken in an agate mortar with some ethanol and thoroughly ground for about $1 \mathrm{~h}$. The resultant mixtures were then allowed to dry for about $1 \mathrm{~h}$ at $60^{\circ} \mathrm{C}$. This was followed by calcination of the samples at $600^{\circ} \mathrm{C}$ for $2 \mathrm{~h}$. For this group of samples, $\mathrm{Y}^{3+}$-doped $\mathrm{PC}$ samples were prepared again along with the other two sets ( $\mathrm{Yb}^{3+}$ and $\mathrm{Gd}^{3+}$ doped) following the SSR route.

2.2. Measurements. All the samples were characterized by scanning electron microscopy (SEM) and powder X-ray diffraction (XRD). The SEM pictures were taken on a Jeol JSM5600 scanning electron microscope from Jeol, Japan. XRD was carried out on a Shimadzu D6000 diffractometer (Shimadzu, Japan) using $\mathrm{Cu}-\mathrm{K} \alpha$ radiation $(\lambda=1.5406 \AA)$.

The visible-light photocatalytic activity of all the samples in the degradation of the dye CR was carried out in a locally fabricated photoreactor. Fabrication and operational details [7, 19] about the photoreactor and optimization of the measurements [5] are reported elsewhere. A solution with $25 \mathrm{mg}$ of CR per liter of water was prepared for the photocatalysis experiment. $850 \mathrm{~mL}$ of this experimental solution along with $275 \mathrm{mg}$ of photocatalyst sample and a stirring bar were placed in the photoreactor. To start the photoreaction, the fluorescent lamp in the reactor chamber was turned on. Throughout the duration of experiment, the solution was kept stirred. At predetermined intervals, $1.5 \mathrm{~mL}$ of the solution was taken out from the photoreactor and centrifuged. Absorbance of the resulting clear solution was 


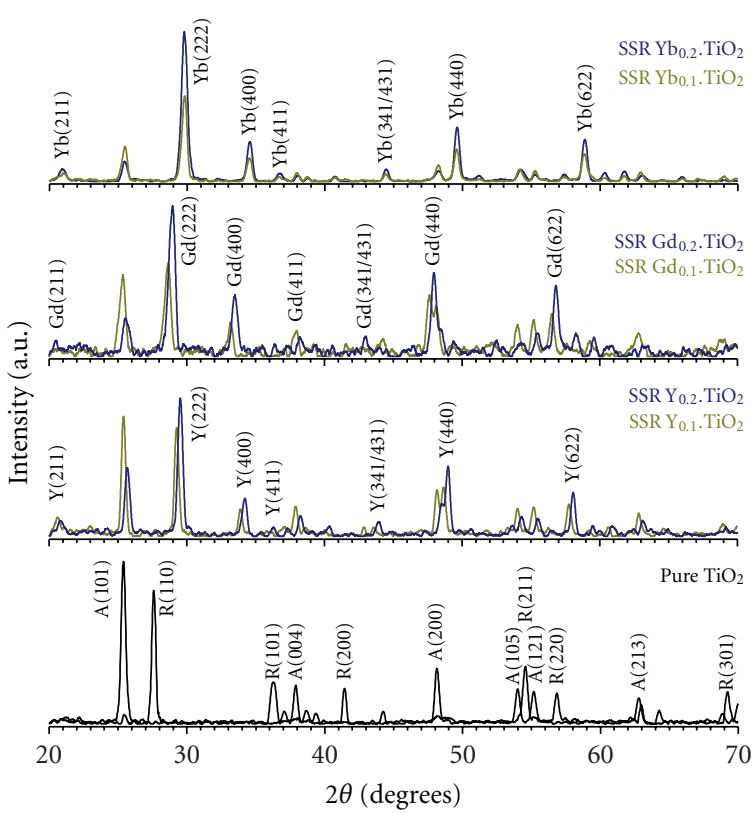

(a)

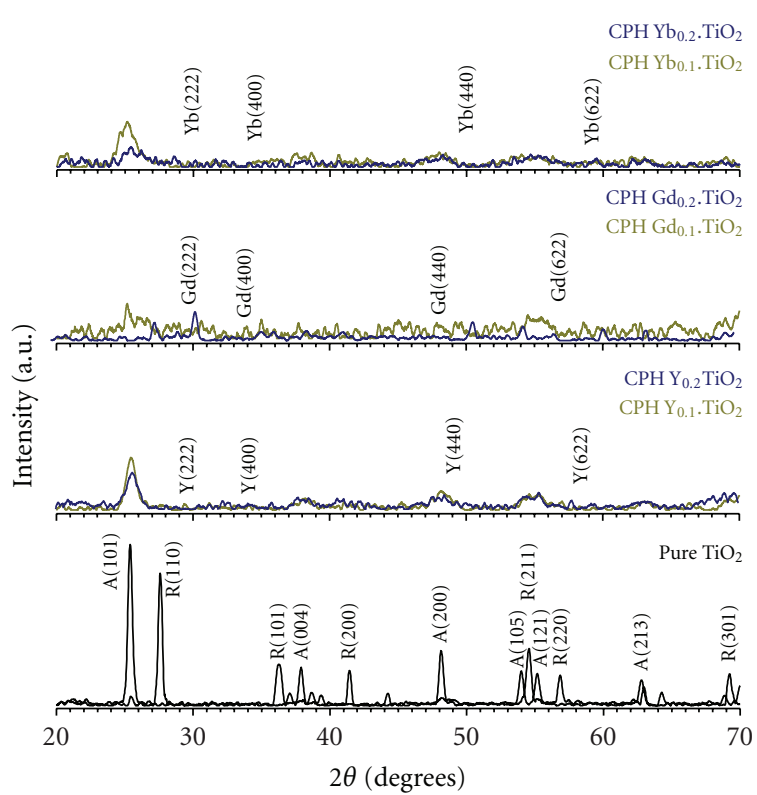

(b)

Figure 2: X-ray diffraction patterns for $\left[\mathrm{R}_{2} \mathrm{O}_{3}\right]_{x} \cdot\left[\mathrm{TiO}_{2}\right]_{1-x}$ composites along with that of pure $\mathrm{TiO}_{2}$. (a) Polycrystalline samples prepared through solid state reaction route. (b) Nanocomposites synthesized by coprecipitation/hydrolysis. R: Rutile; $\mathrm{A}: \mathrm{Anatase}_{\mathrm{Y}} \mathrm{Y}: \mathrm{Y}_{2} \mathrm{O}_{3} ; \mathrm{Gd} \mathrm{Gd}_{2} \mathrm{O}_{3}$; $\mathrm{Yb}: \mathrm{Yb}_{2} \mathrm{O}_{3}$.

recorded at $498 \mathrm{~nm}$ (absorption peak of CR) using a UVVis Shimadzu model 1201 spectrophotometer. Following the same procedure, the dependence of degradation on the catalyst and light alone was also examined. For this, the absorbance of the solutions with photocatalyst samples but in the absence of light, as well as in light but without any sample, was measured.

\section{Results and Discussion}

3.1. X-Ray Diffraction. The X-ray diffraction (XRD) patterns of the rare earth-doped $\mathrm{TiO}_{2} \mathrm{NC}$ samples are depicted in Figure 2. For comparison, the XRD results for the PC materials with similar compositions, and for pure $\mathrm{TiO}_{2}$ (both anatase and rutile phases) are also shown. Sharper peaks obtained with the PC samples correspond to more crystalline structure and larger particle size. The position of various peaks in these plots facilitates proper analysis of the XRD data as well as identification of various phases in the NC samples.

Presence of cubic $\mathrm{R}_{2} \mathrm{O}_{3}[\mathrm{R}=\mathrm{Y}, \mathrm{Gd}, \mathrm{Yb}]$ phases is obvious from the corresponding reflection peaks, associated with the (211), (222), (400), (411), (431/341), (440), and (662) planes, clearly seen in the XRD plots of PC samples [Figure 2(a)]. However, due to their smaller particle size, the XRD patterns of the corresponding NC samples [Figure 2(b)] show broadened peaks with much reduced heights. Additionally, the most prominent anatase peak associated with (101) reflection plane around $2 \theta=25.7^{\circ}$ establishes the presence of that phase in all the doped samples (PC and NC). Other anatase peaks visible in the
XRD data for composites, especially of the PC samples, are those corresponding to (200), (105), (121) and (213) reflection planes around $2 \theta=48.8^{\circ}, 54.8^{\circ}, 54.9^{\circ}$, and $63.1^{\circ}$, respectively. However, all these significant peaks show small shifts relative to those visible in the XRD plot for pure anatase, indicating that the doped ions occupied the lattice sites and deformed it. For example, the (101) peak has shifted to $2 \theta=25.5^{\circ}$ and $25.4^{\circ}$ (for $x=0.1$ and $0.2 \mathrm{Y}$ doping, resp.), to $2 \theta=7.6^{\circ}$ and $25.6^{\circ}$ (for $x=0.1$ and $0.2 \mathrm{Gd}$ doping, resp.), and to $2 \theta=25.2^{\circ}$ and $25.6^{\circ}$ (for $x=0.1$ and $0.2 \mathrm{Yb}$ doping, resp.). It can also be noted that for $x=0.1$ doping, in general, this shift is larger as compared to that for $x=$ 0.2 doping, which probably implies that more ions tend to occupy the lattice sites at smaller doping concentration. At higher concentration, on the other hand, less dopant ions move inside the crystal sites and part of the latter remains in the $\mathrm{R}_{2} \mathrm{O}_{3}$ phase, probably forming interstitial clusters or islands within the bulk of the composites. In the XRD data therefore, both the lattice deformations, as well as the peaks corresponding to pure oxide phases, are observed. Nevertheless, the overall homogeneity of the composites was not compromised by either of these two substitution processes, which was confirmed by the repeatability of XRD results. With increased doping concentration, the increasing heights of the $\mathrm{R}_{2} \mathrm{O}_{3}$ peaks, and the associated decrease in heights of the anatase peaks, suggest the trend of changing fraction of these materials in the composites. However, the XRD results do not show any new, unexpected peaks, which means that no new phases were formed during either of the synthesis processes. In other words, the crystallographic properties of the individual rare earth oxides were retained in the composites. 
3.2. Particle Size Analysis. The SEM pictures of chemically synthesized NCs show grains of approximately 70-80 nm size. A typical SEM picture is depicted in Figure 3. The crystallite size (estimated from the XRD data using Scherrer formula $[5-7,20])$, which is entirely different from the grainsize of the samples, is defined as the smallest possible volumes of the sample that reflect the incident X-rays coherently. Grains, on the other hand, are independent particles of the sample that may be visible under a microscope, such as SEM, at suitable magnification. We have already estimated that a single grain of the PC sample could consist of several thousands of crystallites, whereas that of the NCs would have only about a few tens of them [5]. Obviously, it is the surface area of the grains (which are effectively agglomerations of the crystallites), which is exposed to, and thus available for the chemical processes such as photosensitization. Nevertheless, there is a clear correlation between the two sizes: smaller crystallites usually agglomerate into smaller grains and vice verse. Most of the authors have reported particle-sizedependent effects of photocatalysts in terms of crystallite size $z$, even though it has been termed as particle-size in their work (e.g., see [9]). In this paper, for the sake of consistency, we will follow the same methodology for comparison of sizedependent effects.

Particle (i.e., crystallite) size of each sample was estimated using Scherrer formula $[5-7,20]$ from the FWHM of Gaussian best-fit to three to four most prominent peaks in the XRD data. The value of $z$ for the as-received anatase $\mathrm{TiO}_{2}$ powder was estimated to be around $47 \mathrm{~nm}$. For the doped samples, average value of $z$ for NCs was found to be within 12 to $19 \mathrm{~nm}$ (see Table 1). On the other hand, average $z$ ranging from nearly 34 to $56 \mathrm{~nm}$ was estimated for PC samples. For both size groups, that is, for both types of sample preparation methods employed, the smallest particles were produced with $\mathrm{Gd}^{3+}$ ions, and the largest with $\mathrm{Y}^{3+}$ ions doping.

3.3. Photocatalysis Results. The visible light-induced photocatalytic activity of all the samples was assessed through the degradation of CR dye. Corresponding to each of the catalysts, the efficiency of degradation was evaluated in terms of apparent rate constant $\left(k_{\mathrm{obs}}\right)$, and the percent degradation of CR after 180 minutes $\left(C_{180}^{\prime}\right)$. For the estimation of $k_{\mathrm{obs}}$, the method of least-square regression was employed to $\ln \left(C / C_{0}\right)$ versus time data. All NC samples showed better degradation of CR at faster rates as compared to the PC samples. Rate of degradation for all the catalysts was found to be of first order. Figure 4 shows the relative percent degradation of CR in the presence of various catalysts as a function of time. The control experiments performed with photocatalysts in the absence of irradiation, as well as in light alone without any sample, did not produce any significant degradation of CR [shown in Figure 4(c)]. This implies that both the catalyst and the visible light are simultaneously required for degradation. In the following section, we discuss the photocatalytic activity for each type of doping separately, and then compare the results.

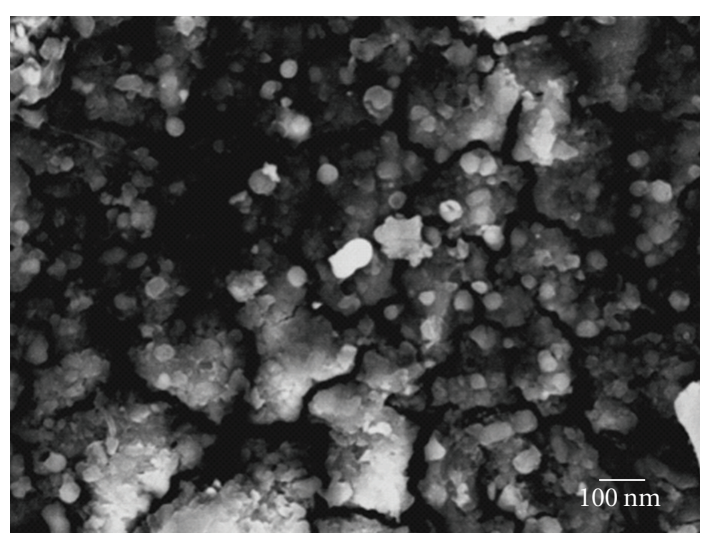

Figure 3: A typical SEM picture of $\left[\mathrm{Y}_{2} \mathrm{O}_{3}\right]_{x} \cdot\left[\mathrm{TiO}_{2}\right]_{1-x}$ nanocomposite (for $x=0.1$ composition).

$Y^{3+}$-Doped Composites. Both in terms of the $k_{\mathrm{obs}}$ as well as $C_{180}^{\prime}$, best degradation results were obtained with the $\mathrm{Y}^{3+}$ doped samples. All the composites (NCs or PCs) produced much better degradation than the as-received pure $\mathrm{TiO}_{2}$. In contrast to pure $\mathrm{TiO}_{2}$, which took about $120 \mathrm{~min}$ to degrade CR to half of its starting concentration, both $\mathrm{Y}^{3+}$ NCs (with $x=0.1,0.2$ ) took only about $30 \mathrm{~min}$. Highest value of $k_{\mathrm{obs}}$ (about $2.74 \times 10^{-2} \mathrm{~min}^{-1}$ ) among all the samples, investigated in this work, was obtained with $x=0.1$ $\mathrm{Y}^{3+}$ doped NC sample, which degraded $91 \%$ of CR in 180 minutes. For the other NC $(x=0.2)$ of this set, $C_{180}^{\prime}$ was found to be $95 \%$, even though this sample had marginally smaller value of $k_{\mathrm{obs}}=2.62 \times 10^{-2} \mathrm{~min}^{-1}$. For the $\mathrm{Y}^{3+}$ doped PC samples, values of $k_{\text {obs }}$ were estimated to be 0.79 $\times 10^{-2}$ and $0.89 \times 10^{-2} \mathrm{~min}^{-1}$, with $C_{180}^{\prime}$ as high as 75 and $79 \%$, respectively, for $x=0.1$ and 0.2 molar fractions.

$\mathrm{Yb}^{3+}$-Doped Composites. Among the three sets of composites, the values of $k_{\mathrm{obs}}$ and $C_{180}^{\prime}$ for $\mathrm{Yb}^{3+}$-doped samples were found to be intermediate. The NCs of this set showed reasonably good degradation, which was better than that of as-received pure $\mathrm{TiO}_{2}$. In about $60 \mathrm{~min}$, both NCs degraded the initial amount of CR to nearly half of it, with $k_{\text {obs }}$ values being around $1.02 \times 10^{-2} \mathrm{~min}^{-1}$ and $0.87 \times 10^{-2} \mathrm{~min}^{-1}$, and $C_{180}^{\prime}$ values about 85 and $80 \%$, respectively, for the $x=0.1$ and 0.2 molar fractions. The corresponding values for the $x=0.1$ and 0.2 PC samples were estimated to be around $0.53 \times 10^{-2} \mathrm{~min}^{-1}$ and $0.78 \times 10^{-2} \mathrm{~min}^{-1}$; and 61 and $75 \%$, respectively. As compared to the as-received pure $\mathrm{TiO}_{2}$, all composites of this set showed better photocatalytic activity, except the $x=0.1$ PC sample, which showed nearly the same activity as the pure material.

$G d^{3+}$-Doped Composites. The composites doped with $\mathrm{Gd}^{3+}$ showed poor photocatalytic properties as compared to the other two doping types. For the NCs of this set, it took more than $60 \mathrm{~min}$ to degrade $\mathrm{CR}$ to half of its initial concentration, though it was still better than that of as-received pure $\mathrm{TiO}_{2}$, which took nearly $120 \mathrm{~min}$ for the same amount of degradation. For this set, the maximum degradation of $C_{180}^{\prime}=80 \%$ was obtained with $x=0.1$ $\mathrm{NC}$ at a rate $k_{\mathrm{obs}}=0.87 \times 10^{-2} \mathrm{~min}^{-1}$. The other NCs 

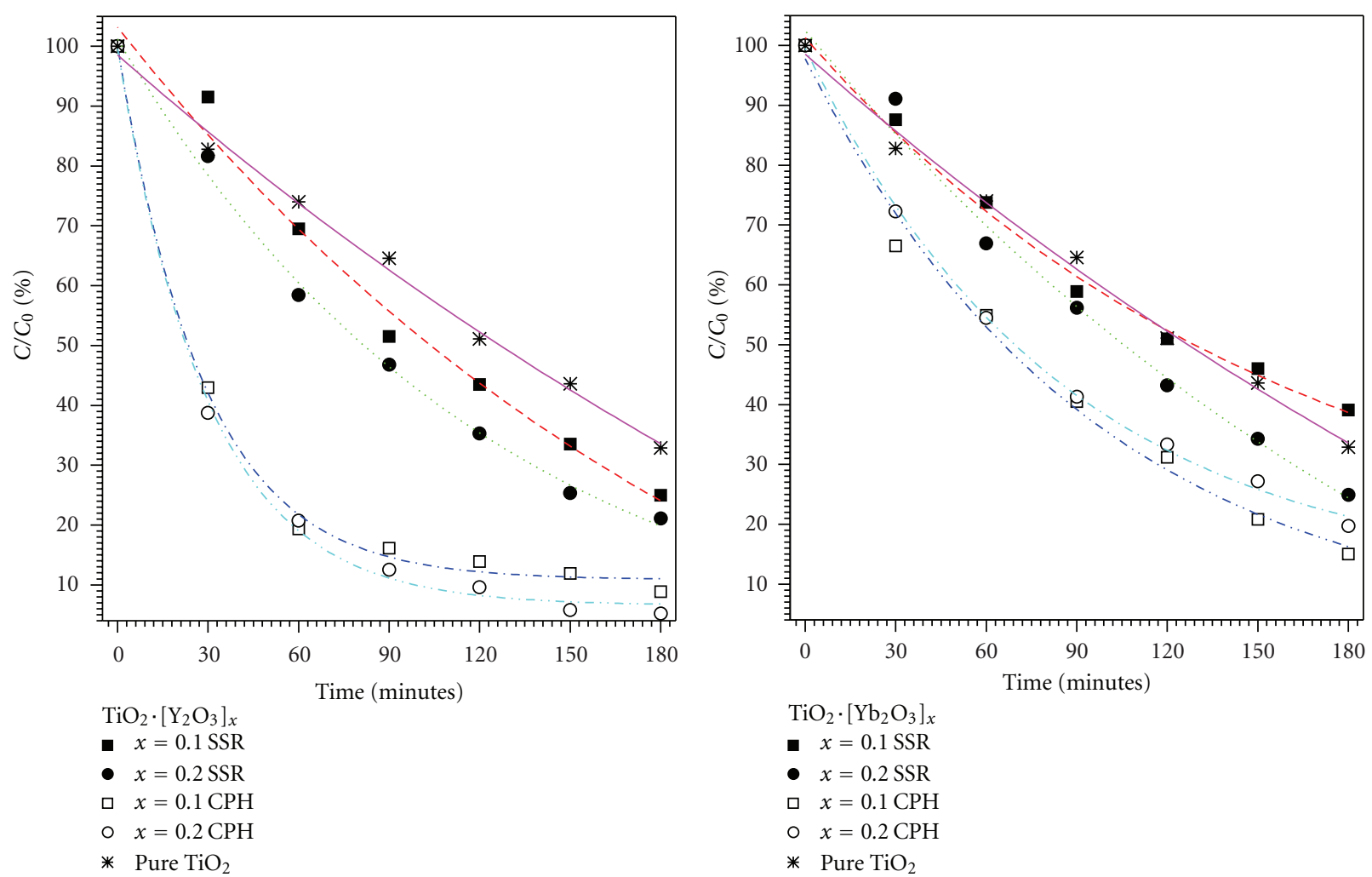

(a)

(b)

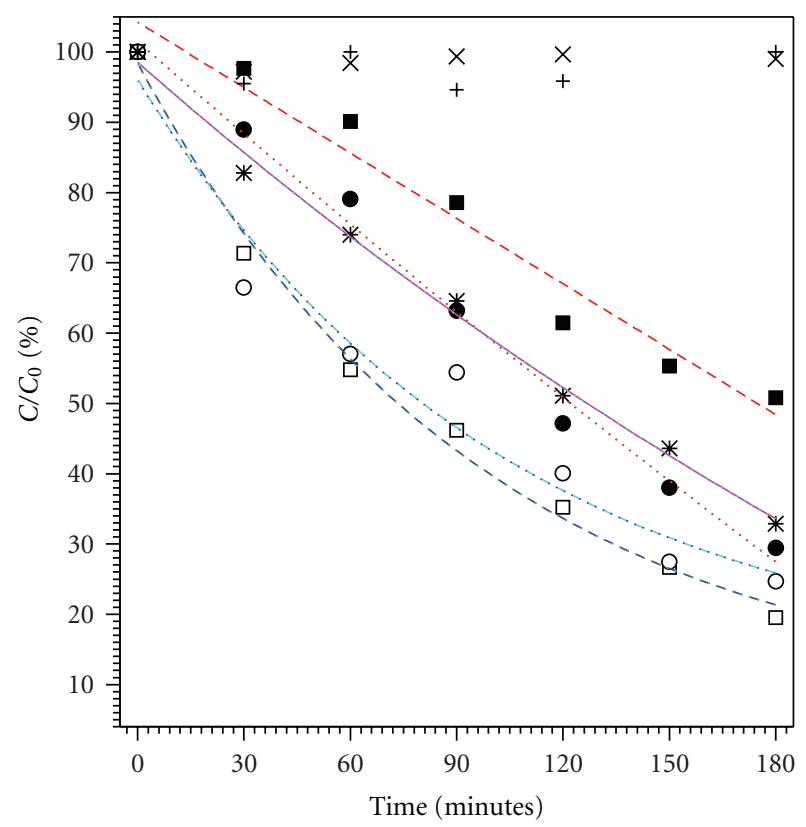

$\mathrm{TiO}_{2} \cdot\left[\mathrm{Gd}_{2} \mathrm{O}_{3}\right]_{x}$

+ Without catalyst

ㅁ $x=0.1 \mathrm{CPH}$

$\times$ Without light

○ $x=0.2 \mathrm{CPH}$

- $x=0.1 \mathrm{SSR}$

* Pure $\mathrm{TiO}_{2}$

- $x=0.2 \mathrm{SSR}$

(c)

FIgure 4: Photocatalytic degradation with time of Congo red in the presence of $\left[\mathrm{R}_{2} \mathrm{O}_{3}\right]_{x} \cdot\left[\mathrm{TiO}_{2}\right]_{1-x}$ composites; (a) $\mathrm{Y}^{3+}$-doped samples, (b) $\mathrm{Yb}^{3+}$-doped samples, and (c) $\mathrm{Gd}^{3+}$-doped samples with the results of experiments without any catalyst $(+)$, and in the absence of light irradiation $(\times)$. The degradation with commercial $\mathrm{TiO}_{2}$ is also shown for comparison. The lines represent the best-fit curves. 
TABLE 1: Summary of results.

\begin{tabular}{|c|c|c|c|c|c|}
\hline Samples & Molar fraction $x$ & Particle size $z(\mathrm{~nm})$ & $t_{1 / 2}(\min )$ & $C_{180}^{\prime}{ }^{*}(\%)$ & $k_{\mathrm{obs}}{ }^{* *}\left(\times 10^{-2} \mathrm{~min}^{-1}\right)$ \\
\hline \multirow{2}{*}{$\mathrm{CPH} \mathrm{Gd} \cdot \mathrm{TiO}_{2}$} & 0.1 & 12 & 60 & 80 & 0.87 \\
\hline & 0.2 & 12 & 60 & 75 & 0.75 \\
\hline \multirow{2}{*}{$\mathrm{CPH} \mathrm{Yb} \cdot \mathrm{TiO}_{2}$} & 0.1 & 13 & 60 & 85 & 1.02 \\
\hline & 0.2 & 13 & 60 & 80 & 0.87 \\
\hline \multirow{2}{*}{$\mathrm{CPH} \mathrm{Y} \cdot \mathrm{TiO}_{2}$} & 0.1 & 16 & 30 & 91 & 2.74 \\
\hline & 0.2 & 19 & 30 & 95 & 2.62 \\
\hline Commercial $\mathrm{TiO}_{2}{ }^{+}$ & 0.0 & 57 & 120 & 67 & 0.59 \\
\hline \multirow{2}{*}{$\mathrm{SSR} \mathrm{Gd} \cdot \mathrm{TiO}_{2}$} & 0.1 & 37 & 180 & 49 & 0.42 \\
\hline & 0.2 & 34 & 120 & 70 & 0.71 \\
\hline \multirow{2}{*}{$\mathrm{SSR} \mathrm{Yb} \cdot \mathrm{TiO}_{2}$} & 0.1 & 43 & 120 & 61 & 0.53 \\
\hline & 0.2 & 36 & 90 & 75 & 0.78 \\
\hline \multirow{2}{*}{ SSR Y $\cdot \mathrm{TiO}_{2}$} & 0.1 & 45 & 90 & 75 & 0.79 \\
\hline & 0.2 & 56 & 75 & 79 & 0.89 \\
\hline
\end{tabular}

${ }^{*}$ After 180 minutes. ${ }^{* *}$ First order fitting. ${ }^{+}$As received pure anatase powder used in SSR samples.

with $x=0.2$ showed $75 \%$ degradation $\left(C_{180}^{\prime}\right)$ with $k_{\mathrm{obs}}=$ $0.75 \times 10^{-2} \mathrm{~min}^{-1}$. Photocatalytic activity shown by the PC samples of $\mathrm{Gd}^{3+}$ doped set was worse (for $x=0.1$ ) than or nearly the same (for $x=0.2$ ) as that of pure $\mathrm{TiO}_{2}$. The PC sample with $x=0.1$ degraded only about $49 \%\left(C_{180}^{\prime}\right)$ of CR with $k_{\mathrm{obs}}=0.42 \times 10^{-2} \mathrm{~min}^{-1}$, and that with $x=0.2$ degraded $70 \%\left(C_{180}^{\prime}\right)$ with $k_{\mathrm{obs}}=0.71 \times 10^{-2} \mathrm{~min}^{-1}$.

3.4. Comparison of Results. As reported in some of our recent reports [5-7], the $\mathrm{e}^{-} / \mathrm{h}^{+}$recombination seems to be the most significant factor that severely hampers the efficiency of photocatalytic degradation. The major role of doping is to minimize the rate of charge recombination. Since the rare earth ions are known for trapping the electrons efficiently $[15,16]$, they could be suitable choice for doping. In terms of doping alone, the overall photocatalytic activity of $\mathrm{Y}^{3+}$ doped composites was found to be the best among all doping types, followed by $\mathrm{Yb}^{3+}$ - and $\mathrm{Gd}^{3+}$-doped sets, respectively. Therefore, presence of $\mathrm{Y}^{3+}$ ions apparently suppresses the recombination more efficiently than $\mathrm{Yb}^{3+}$ and $\mathrm{Gd}^{3+}$ ions. However, there are other factors too, which could play important roles in determining the final degradation results.

It is more or less established that particle size plays a very significant role in photocatalytic activity [5, 9]. Smaller particles offer larger specific surface area in the process of photosensitization and thus support the degradation of contaminate molecules adsorbed to the catalyst surface. Therefore, the NCs expectedly produced better degradation of CR than the corresponding PC samples with similar compositions, under similar experimental conditions, for each of the three sets of composites investigated in this work. However, it is also noteworthy that when the particle size is too small $(\leq 10 \mathrm{~nm})$, rate of recombination becomes significantly high [9] because of the smaller free path available to the charges, which may also reduce the degradation efficiency appreciably.

A third point also needs attention before the analysis of observed results. The band gaps of $\mathrm{Y}_{2} \mathrm{O}_{3}, \mathrm{Gd}_{2} \mathrm{O}_{3}$, and $\mathrm{Yb}_{2} \mathrm{O}_{3}$ are $4.5,5.4$, and $4.9 \mathrm{eV}$, respectively, which correspond to the cut-off wavelengths $\lambda_{\text {cutoff }}$ (absorption band-edge) of 275 , 230 and $253 \mathrm{~nm}$, respectively. The wavelength of $275 \mathrm{~nm}$ falls inside the UV-C region of the spectrum, while the other two in the middle ultra-violet (MUV) region. In their pure forms, therefore, these rare earth oxides can absorb only the UV light, and hence the possibility of visible light induced photocatalysis is completely ruled out. We have also tested and found that these oxides in their pure forms did not lead to any photocatalytic degradation of CR under visible light irradiation. Therefore, in the doped samples, only the active part, that is, the fraction of $\mathrm{TiO}_{2}$, should be responsible for the degradation of $\mathrm{CR}$, and role of the doped rare earth oxides should be significant only in so far as the suppression of unwanted $\mathrm{e}^{-} / \mathrm{h}^{+}$recombination is concerned. In addition, the XRD results did not reveal any sign of new phase formation, which implies that probably no modification of band-gap took place during synthesis. All these points essentially suggest that better photocatalytic degradation observed with the doped composites in this work may not be associated with a doping induced modification of band-gap, or to the process of photoexcitation.

In a certain degradation process, all the above mentioned factors act together and the final results are determined by their net, simultaneous influence. It is very difficult to distinguish their individual contributions to the net degradation, and therefore, a detailed analysis of results is required.

Among the NCs, even with the largest particle size of 16 $(x=0.1)$ and $19(x=0.2) \mathrm{nm}, \mathrm{Y}^{3+}$-doped samples produced better photocatalytic degradation as compared to other doping types. This may be attributed, as mentioned above, to a more efficient suppression of $\mathrm{e}^{-} / \mathrm{h}^{+}$recombination by the $\mathrm{Y}^{3+}$ ions. For the other two doping types $\left(\mathrm{Gd}^{3+}\right.$ and $\left.\mathrm{Yb}^{3+}\right)$, the $\mathrm{e}^{-} / \mathrm{h}^{+}$recombination was probably not suppressed as much as it was with the $\mathrm{Y}^{3+}$ ions, which should have led to their inferior photocatalytic activity. The poor suppression of recombination was apparently due to their smaller particle size of about $12 \mathrm{~nm}$ (both $\mathrm{Gd}^{3+}$ doped NCs) and $13 \mathrm{~nm}$ (both 
$\mathrm{Yb}^{3+}$ doped NCs), which were too close to the critical $10 \mathrm{~nm}$ size. Therefore, the higher rate of $\mathrm{e}^{-} / \mathrm{h}^{+}$recombination may have been partly responsible for the inferior photocatalytic activity of $\mathrm{Gd}^{3+}$ and $\mathrm{Yb}^{3+}$ doped $\mathrm{NCs}$ as compared to their $\mathrm{Y}^{3+}$ doped counterparts. Nevertheless, this conclusion needs to be tested in context with what happens with larger particles, that is, with the PC samples.

Taking one type of doping at a time, one can throw some more light on the underlying processes. For both $\mathrm{Gd}^{3+}-$ doped NCs, the particle size was about $12 \mathrm{~nm}$, and it was about $13 \mathrm{~nm}$ for both $\mathrm{Yb}^{3+}$-doped NCs. However, in both of these sets an increase of doping by 0.1 molar fraction (i.e., $100 \%$ increase of doping) resulted in about $5 \%$ (equivalent to about $6 \%$ of the value with $x=0.1$ ) decrease in $C_{180}^{\prime}$, and a decrease of about $0.12 \times 10^{-2} \mathrm{~min}^{-1}$ and $0.15 \times 10^{-2} \mathrm{~min}^{-1}$, respectively, for $\mathrm{Gd}^{3+}$ - and $\mathrm{Yb}^{3+}$-doped NCs (both equivalent to about $15 \%$ of the corresponding values with $x=0.1$ ) in $k_{\text {obs. }}$. Since the particle size, and hence presumably the rate of recombination too, was nearly the same for both doping concentrations of each doping types, such a decrease in $C_{180}^{\prime}$ and $k_{\text {obs }}$ can only be attributed to the decrease in active part of the catalyst, that is, the fraction of $\mathrm{TiO}_{2}$. It may easily be calculated that when the molar fraction increases from $x=$ 0.1 to $x=0.2$, the amount of $\mathrm{TiO}_{2}$ decreases by about $30 \%$ in both $\mathrm{Gd}^{3+}$ - and $\mathrm{Yb}^{3+}$-doped sets. The decreased fraction of $\mathrm{TiO}_{2}$ adequately explains the observed $6 \%$ and $15 \%$ decrease, respectively, in $C_{180}^{\prime}$ and $k_{\mathrm{obs}}$ of $\mathrm{Gd}^{3+}$ - and $\mathrm{Yb}^{3+}$-doped NCs with $100 \%$ increase in doping.

In contrast, the $\mathrm{Y}^{3+}$-doped NCs showed nearly $4 \%$ (about $4 \%$ with respect to the value for $x=0.1$ ) increase in $C_{180}^{\prime}$, and only about $0.12 \times 10^{-2} \mathrm{~min}^{-1}$ (also nearly $4 \%$ of the value with $x=0.1$ ) decrease in $k_{\text {obs }}$ with a $100 \%$ increase of doping (from 0.1 to 0.2 molar fraction). However, in this set, the same increase of doping was associated with only about $23 \%$ decrease in the fraction of $\mathrm{TiO}_{2}$. Thus, higher amount of $\mathrm{TiO}_{2}$ was available in $\mathrm{Y}^{3+}$-doped, $x=0.2 \mathrm{NC}$ as compared to other NCs doped with same molar fraction of $\mathrm{Gd}^{3+}$ and $\mathrm{Yb}^{3+}$. Additionally, the $x=0.2 \mathrm{NC}(19 \mathrm{~nm})$ was about $19 \%$ larger in particle size than $x=0.1 \mathrm{NC}$ $(16 \mathrm{~nm})$. As mentioned earlier, higher fraction of $\mathrm{TiO}_{2}$ in the samples leads to improved degradation (increased values of $C_{180}^{\prime}$ and $k_{\mathrm{obs}}$ ), while a larger particle size tends to reduce them. Obviously, the net activity should be a combined, simultaneous effect of these two factors, which explains why $\mathrm{Y}^{3+}$-doped NCs showed, when the molar concentration was doubled, a small increase in $C_{180}^{\prime}$ value, instead of a decrease as seen with other dopings; and why there was only about $4 \%$ decrease in $k_{\mathrm{obs}}$ as compared to nearly $15 \%$ drop observed with the other doping types.

For the SSR produced PC composites, the particle size effects on the observed degradation were more pronounced and along the expected lines for $\mathrm{Gd}^{3+}$ - and $\mathrm{Yb}^{3+}$-doped samples. Smaller particle size (PC samples of $\mathrm{Gd}^{3+}$ - and $\mathrm{Yb}^{3+}$-doped sets with molar fraction $x=0.2$ ) led to better degradation of CR and vice versea. Quantitatively, the particles smaller by nearly $3 \mathrm{~nm}$ (i.e., about $8 \%$ ) and $7 \mathrm{~nm}$ (about $16 \%$ ) in size, of $\mathrm{Gd}^{3+}$ - and $\mathrm{Yb}^{3+}$-doped samples, respectively, resulted in improving the values of $C_{180}^{\prime}$ by $21 \%$ (equivalent to about $43 \%$ of the value with $x=0.1$ ) and $14 \%$ (about 23\%) and that of $k_{\text {obs }}$ by $0.29 \times 10^{-2} \mathrm{~min}^{-1}$ (about $69 \%$ ) and $0.25 \times 10^{-2} \mathrm{~min}^{-1}$ (about $47 \%$ ), respectively. Such large improvements cannot be attributed solely to the reduced particle size, also because they were observed even as the molar concentration was doubled, which meant a loss of $\mathrm{TiO}_{2}$ fraction (by approximately $30 \%$ ) in both the $x=0.2$ samples. However, due to the particle size ( 34 to $43 \mathrm{~nm}$ ) that was much larger than the critical $10 \mathrm{~nm}$, the rate of recombination was not as high in these PC composites, as it was in the case of NCs with similar compositions. As a result, the doped $\mathrm{Gd}^{3+}$ and $\mathrm{Yb}^{3+}$ ions apparently managed to control the recombination substantially and that in turn produced the observed large improvements in degradation of CR. In other words, a combination of positive effects originating from the reduced particle size and efficient suppression of $\mathrm{e}^{-} / \mathrm{h}^{+}$recombination dominated the negative effects associated with the loss of active material, resulting in a net improvement in photocatalytic properties of these PC samples.

For the $\mathrm{Y}^{3+}$-doped PC samples, on the other hand, a completely opposite trend was obtained, in terms of both $C_{180}^{\prime}$ and $k_{\text {obs. }}$. In this set, better degradation was achieved with larger $(56 \mathrm{~nm})$ particles, which eventually had higher molar fraction $(x=0.2)$ of $\mathrm{Y}^{3+}$ ions or smaller fraction of $\mathrm{TiO}_{2}$. In these samples, particles that were $11 \mathrm{~nm}$ (about $24 \%$ ) larger than the other helped $C_{180}^{\prime}$ and $k_{\mathrm{obs}}$ increase by $4 \%$ (about $5 \%$ with respect to the $x=0.1$ PC sample) and $0.10 \times 10^{-2} \mathrm{~min}^{-1}$ (nearly $13 \%$ ), respectively. At the same time, since the larger samples were doped with $x=$ 0.2 molar fraction of $\mathrm{Y}^{3+}$ ions, they had about $23 \%$ less $\mathrm{TiO}_{2}$ as compared to the $x=0.1 \mathrm{PC}$ sample. Despite these two retarding factors, the $x=0.2$ sample led to better degradation of CR than the $x=0.1$-doped PC sample. Obviously, it is the third factor, that is, how efficiently $\mathrm{Y}^{3+}$ ions-checks the $\mathrm{e}^{-} / \mathrm{h}^{+}$recombination, that not just compensated for the impeding parts, but also improved the degradation properties significantly. Very clearly, it implies that presence of $\mathrm{Y}^{3+}$ ions checks the $\mathrm{e}^{-} / \mathrm{h}^{+}$recombination much more efficiently than the other two doping types studied in this work.

Evidently, the $\mathrm{Y}^{3+}$ ion-doped composites show better degradation in terms of $C_{180}^{\prime}$ and $k_{\mathrm{obs}}$, even with their slightly bigger particle size. It may be noted that these composites contain larger amount of $\mathrm{TiO}_{2}$. Thus, all the above observations point out to some important conclusions: better photocatalysts may be synthesized when the dopants are chosen in such a way that (1) the effective decrease in the fraction of $\mathrm{TiO}_{2}$ in composites is minimum, and (2) the oxidation state of the dopant ions, which controls the $\mathrm{e}^{-} / \mathrm{h}^{+}$ recombination, is maximum. Both these requirements can be satisfied with the doping of lighter rare earth oxides (or, possibly some other oxides also) into the host $\mathrm{TiO}_{2}$. When a suitable dopant is thus identified, an appropriate method of synthesis to produce nanosized catalyst particles should be adopted in order to prepare the catalyst with best degradation efficiency.

Finally, as far as the understanding of the process of $\mathrm{e}^{-} / \mathrm{h}^{+}$recombination is concerned, more work needs to be done. Nevertheless, rare earth ions are well known for their 
electron-trapping properties $[15,16]$. For example, in $\mathrm{Yb}$ doped InP semiconductor, the $\mathrm{Yb}^{3+}$ substituted for the host In forms an isoelectronic acceptorlike trap for electrons at $30 \mathrm{meV}$ below the CB [21]. Similarly, one can expect the formation of electron-traps in $\mathrm{TiO}_{2}$ matrix doped with rareearth ions. The electrons produced in the adsorbed CR molecules through visible-light excitation can be captured by these traps in the $\mathrm{TiO}_{2}$ host, leaving behind the holes to participate in the chemical processes leading to the degradation. This may be one of the possible mechanisms through which the $\mathrm{e}^{-} / \mathrm{h}^{+}$recombination is controlled in the composites studied in this work, and it would clearly depend on the properties of the doped ions and how they are substituted in the $\mathrm{TiO}_{2}$ host. An investigation involving low-temperature photoluminescence spectroscopy and taking into consideration the electronic configurations of the dopant ions may be useful.

\section{Conclusions}

Rare earth ion-doped $\mathrm{TiO}_{2}$ composites $\left[\mathrm{R}_{2} \mathrm{O}_{3}\right]_{x} \cdot\left[\mathrm{TiO}_{2}\right]_{1-x}$ (where $\mathrm{R}: \mathrm{Y}, \mathrm{Yb}, \mathrm{Gd} ; x=0.1,0.2$ ) are generally better photocatalysts than the pure $\mathrm{TiO}_{2}$. Both the $\mathrm{NC}$ and PC samples of these materials degrade the $\mathrm{CR}$ dye quite efficiently under visible light. However, all the NCs showed significantly enhanced photocatalytic activity as compared to pure $\mathrm{TiO}_{2}$ and the PC samples, in terms of both $k_{\text {obs }}$ and $C_{180}^{\prime}$. Best degradation results of $C_{180}^{\prime}=95 \%$, and $k_{\text {obs }}=2.62 \times 10^{-2} \mathrm{~min}^{-1}$ were obtained with the $\mathrm{Y}^{3+}$ doped $\mathrm{NC},\left[\mathrm{Y}_{2} \mathrm{O}_{3}\right]_{0.2} \cdot\left[\mathrm{TiO}_{2}\right]_{0.8} \cdot \mathrm{Yb}^{3+}$ - and $\mathrm{Gd}^{3+}$-doped NCs also produced fairly good degradations. On the other hand, the PC materials with similar compositions showed much less degradation. Among these samples also, the $\mathrm{Y}^{3+}$ doped compositions led to better degradation than others. The observed improvement in photocatalytic properties of the catalysts is directly related to their reduced particle size, which implies that photosensitization is the process responsible for degradation of CR. Further, the results also pointed out that presence of rare earth ions in the composites added to the enhancement through efficient suppression of $\mathrm{e}^{-} / \mathrm{h}^{+}$recombination by trapping the photogenerated electrons.

We conclude that it is possible to synthesize better visible light photocatalysts by suitable choice of dopants and employing appropriate method to produce nanosized particles. The efficiency of the composite photocatalysts is apparently determined by two factors: (1) the fraction of $\mathrm{TiO}_{2}$ in the composites, and (2) the oxidation state and nature of the dopant ions. Combined together, all these points imply that better photocatalysts may be prepared when $\mathrm{TiO}_{2}$ is doped with a lighter ion, but the one with higher oxidation state.

\section{References}

[1] A. L. Linsebigler, G. Lu, and J. T. Yates, "Photocatalysis on $\mathrm{TiO}_{2}$ surfaces: principles, mechanisms, and selected results," Chemical Reviews, vol. 95, no. 3, pp. 735-758, 1995.
[2] K. Hashimoto, H. Irie, and A. Fujishima, " $\mathrm{TiO}_{2}$ photocatalysis: a historical overview and future prospects," Japanese Journal of Applied Physics, Part 1, vol. 44, no. 12, pp. 8269-8285, 2005.

[3] Y. Yao, G. Li, S. Ciston, R. M. Lueptow, and K. A. Gray, "Photoreactive $\mathrm{TiO}_{2}$ /carbon nanotube composites: synthesis and reactivity," Environmental Science and Technology, vol. 42, no. 13, pp. 4952-4957, 2008.

[4] Z. Li, W. Shen, W. He, and X. Zu, "Effect of Fe-doped $\mathrm{TiO}_{2}$ nanoparticle derived from modified hydrothermal process on the photocatalytic degradation performance on methylene blue," Journal of Hazardous Materials, vol. 155, no. 3, pp. 590594, 2008.

[5] H. Narayan, H. Alemu, L. Macheli, M. Thakurdesai, and T. K. Gundu Rao, "Synthesis and characterization of $\mathrm{Y}^{3+}$ doped $\mathrm{TiO}_{2}$ nanocomposites for photocatalytic applications," Nanotechnology, vol. 20, no. 25, Article ID 255601, 8 pages, 2009.

[6] H. Narayan and H. M. Alemu, "Titanium dioxide mediated visible light photocatalysis: effects of particle size and doping," in Advances in Nanotechnology, Z. Bartul and J. Trenor, Eds., vol. 4, chapter 7, pp. 205-219, Nova Science Publishers, New York, NY, USA, 2010.

[7] H. Narayan, H. Alemu, L. Machel, M. Sekota, M. Thakurdesai, and T. K.G. Rao, "Role of particle size in visible light photocatalysis of Congo Red using $\mathrm{TiO}_{2} \cdot\left[\mathrm{ZnFe}_{2} \mathrm{O}_{4}\right]_{x}$ nanocomposites," Bulletin of Materials Science, vol. 32, no. 5, pp. 499-506, 2009.

[8] R. Vogel, K. Pohl, and H. Weller, "Sensitization of highly porous, polycrystalline $\mathrm{TiO}_{2}$ electrodes by quantum sized CdS," Chemical Physics Letters, vol. 174, no. 3-4, pp. 241-246, 1990.

[9] R. K. Wahi, W. W. Yu, Y. Liu et al., "Photodegradation of Congo Red catalyzed by nanosized $\mathrm{TiO}_{2}$," Journal of Molecular Catalysis A, vol. 242, no. 1-2, pp. 48-56, 2005.

[10] R. B. M. Bergamini, E. B. Azevedo, and L. R. R. D. Araújo, "Heterogeneous photocatalytic degradation of reactive dyes in aqueous $\mathrm{TiO}_{2}$ suspensions: decolorization kinetics," Chemical Engineering Journal, vol. 149, no. 1-3, pp. 215-220, 2009.

[11] D. Fabbri, A. B. Prevot, and E. Pramauro, "Effect of surfactant microstructures on photocatalytic degradation of phenol and chlorophenols," Applied Catalysis B, vol. 62, no. 1-2, pp. 21-27, 2006.

[12] M. Ashokkumar, A. Kudo, N. Saito, and T. Sakata, "Semiconductor sensitization by $\mathrm{RuS}_{2}$ colloids on $\mathrm{TiO}_{2}$ electrodes," Chemical Physics Letters, vol. 229, no. 4-5, pp. 383-388, 1994.

[13] J. Liqiang, S. Xiaojun, X. Baifu, W. Baiqi, C. Weimin, and F. Honggang, "The preparation and characterization of La doped $\mathrm{TiO}_{2}$ nanoparticles and their photocatalytic activity," Journal of Solid State Chemistry, vol. 177, no. 10, pp. 3375-3382, 2004.

[14] S. Bingham and W. A. Daoud, "Recent advances in making nano-sized $\mathrm{TiO}_{2}$ visible-light active through rare-earth metal doping," Journal of Materials Chemistry, vol. 21, no. 7, pp. 2041-2050, 2011.

[15] J. Liu, R. Yang, and S. Li, "Synthesis and photocatalytic activity of $\mathrm{TiO}_{2} / \mathrm{V}_{2} \mathrm{O}_{5}$ composite catalyst doped with rare earth ions," Journal of Rare Earths, vol. 25, no. 2, pp. 173-178, 2007.

[16] Y. Xie and C. Yuan, "Characterization and photocatalysis of $\mathrm{Eu}^{3+}-\mathrm{TiO}_{2}$ sol in the hydrosol reaction system," Materials Research Bulletin, vol. 39, no. 4-5, pp. 533-543, 2004.

[17] X. L. Jia, Y. Wang, R. S. Xin, Q. L. Jia, and H. J. Zhang, "Preparation of rare-earth element doped titanium oxide thin films and photocatalysis properties," Key Engineering Materials, vol. 336-338, pp. 1946-1948, 2007. 
[18] Z. M. El-Bahy, A. A. Ismail, and R. M. Mohamed, "Enhancement of titania by doping rare earth for photodegradation of organic dye (Direct Blue)," Journal of Hazardous Materials, vol. 166, no. 1, pp. 138-143, 2009.

[19] J. A. Bumpus, J. Tricker, K. Andrzejewski, H. Rhoads, and M. Tatarko, "Remediation of water contaminated with an azo dye: an undergraduate laboratory experiment utilizing an inexpensive photocatalytic reactor," Journal of Chemical Education, vol. 76, no. 12, pp. 1680-1683, 1999.

[20] F. Boulc'h,, M.-C. Schouler, P. Donnadieu, J.-M. Chaix, and E. Djurado, "Domain size distribution of Y-TZP nano-particles using XRD and HRTEM," Image Analysis \& Stereology, vol. 20, pp. 157-161, 2001

[21] M. A. J. Klik, T. Gregorkiewicz, I. V. Bradley, and J. P. R. Wells, "Optically induced deexcitation of rare-earth ions in a semiconductor matrix," Physical Review Letters, vol. 89, no. 22, pp. 2274011-2274014, 2002. 


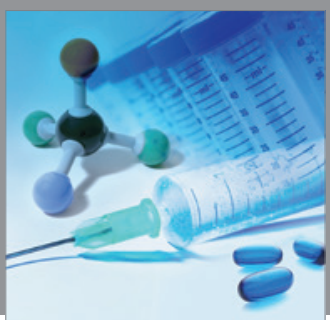

International Journal of

Medicinal Chemistry

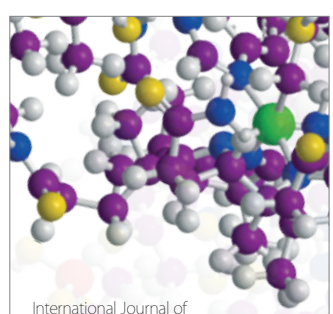

Carbohydrate Chemistry

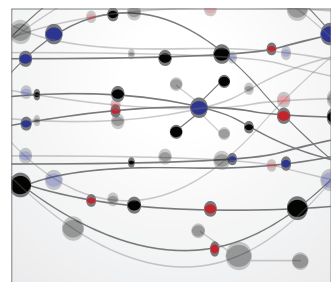

The Scientific World Journal
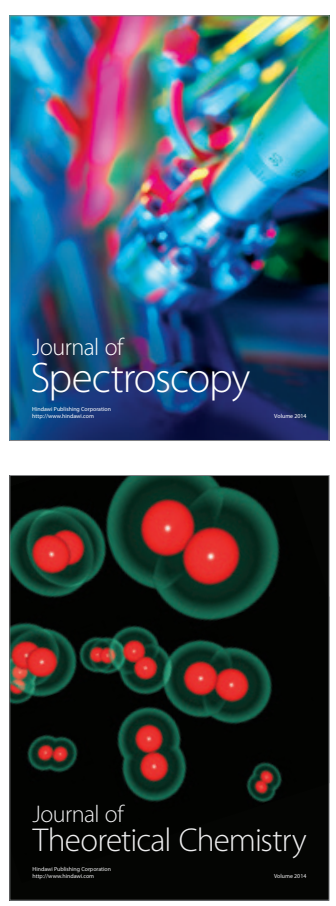
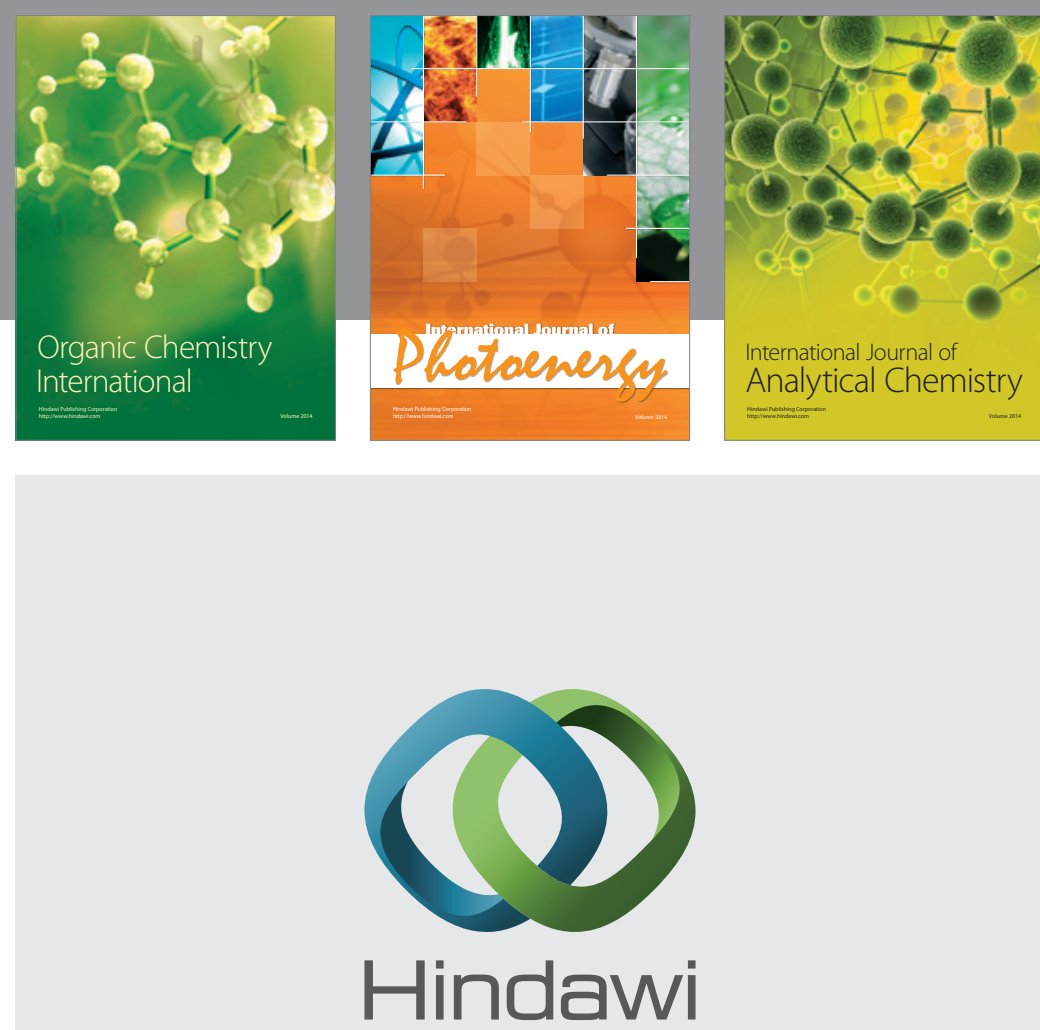

Submit your manuscripts at

http://www.hindawi.com
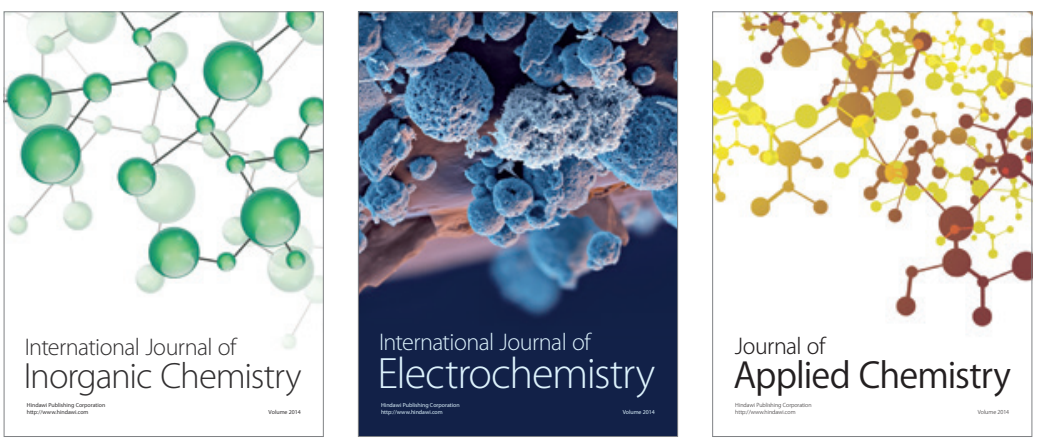

Journal of

Applied Chemistry
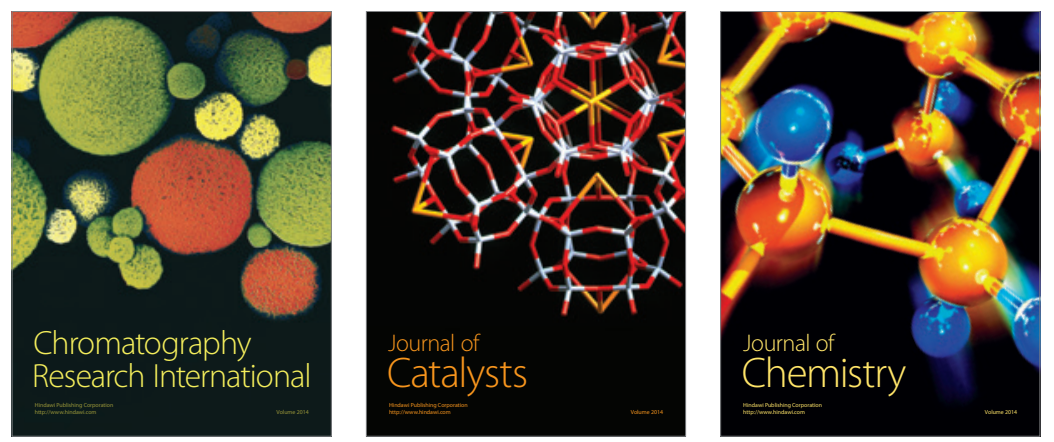
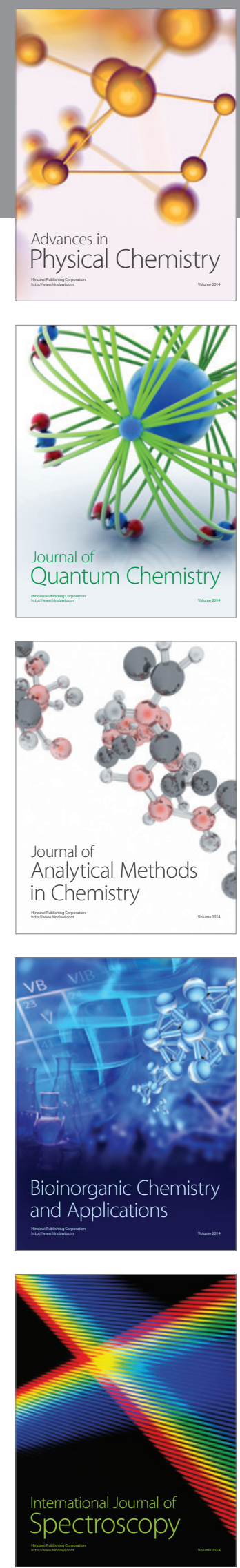